\title{
The perceptions of general practitioners on National Health Insurance in Chris Hani district, Eastern Cape, South Africa
}

\author{
Mthetheleli Mbongeni Gaqavu (i) and Robert Mash* \\ Division of Family Medicine and Primary Care, Stellenbosch University, South Africa \\ *Corresponding author, email: rm@sun.ac.za
}

Background: National Health Insurance (NHI) intends to provide universal health coverage to all South Africans, with equity and quality as its tenets. The participation of private general practitioners (GPs) in NHI is essential. The aim was to explore perceptions of GPs on NHI in Chris Hani district, Eastern Cape, South Africa.

Methods: A descriptive phenomenological qualitative study using semi-structured individual interviews of 12 GPs from six municipalities was undertaken. Data analysis used the framework method assisted by Atlas.ti software.

Results: GPs in Chris Hani district felt that NHI would improve health and benefit society and be of particular benefit to poor and rural people as it will improve access to healthcare. Lack of governmental administrative capacity and a human resource plan were seen as barriers to implementation. They believed that NHI would benefit them through a single purchaser system and support more comprehensive care. GPs were concerned about a lack of information on primary care packages, accreditation, remuneration and patient allocation. They thought that NHI might disadvantage solo GPs. NHI implementation could be improved by actively engaging with GP organisations. Improvement of existing government health facilities and continued medical education were seen as possible ways to better implement $\mathrm{NHI}$.

Conclusion GPs in this study were generally positive about NHI and thought it would benefit both patients and providers. However, they had concerns regarding the capacity of government to implement NHI and the implications for solo GPs, and needed more information. Government needs to actively engage GPs.

Keywords: general practice, national health insurance, primary care, primary health care, Universal health coverage

\section{Introduction}

The South African health system is struggling and people in greatest need still have the least access to health care. ${ }^{1}$ The public healthcare system caters for $84 \%$ of the population and spends $4.2 \%$ of gross domestic product (GDP), while private health care looks after $16 \%$ of the population and spends a further $4.1 \%$ of GDP. ${ }^{1}$ Expenditure on health care is therefore inequitably distributed and, despite spending $8.3 \%$ of GDP, South Africa still has a high burden of disease and health outcomes that are not commensurate with this expenditure. The public health sector is struggling to improve the quality of care and private health care costs have been spiralling out of control. ${ }^{1}$ In 2011, the national Minister of Health introduced the National Health Insurance (NHI) Green Paper to parliament. ${ }^{2}$ This proposed health system reform was intended to provide universal health coverage, and improve social justice and health equity.

The idea of National Health Insurance began with the 1928 Commission on Old Age Pensions and National Insurance. ${ }^{3}$ This was followed by the 1935 Committee of Enquiry into National Health Insurance. ${ }^{3}$ All these initiatives proposed that health insurance be introduced to cover healthcare benefits for low-income employees, although none of the plans were implemented. ${ }^{3}$ The 1942-1944 National Health Services Commission, in contrast to the above, recommended the introduction of a national health tax to provide free healthcare services for all South Africans, but this was also never implemented. ${ }^{3}$

$\mathrm{NHI}$ is not only a funding model for health care. Its goal is to bring universal healthcare coverage to all South Africans. ${ }^{4}$ The current two sectors of public and private health care will be merged into one healthcare system. There will be a health tax to fund NHI and membership will be mandatory for all South Africans. ${ }^{4}$

$\mathrm{NHI}$ will purchase services from accredited hospitals, pharmacies, general practitioners (GPs), dentists and other health professionals. The major difference from the current system will be pricing for the services. The fee for the service model currently in use has resulted in high costs; $\mathrm{NHI}$ will pay providers based on a defined health service package and a capitationbased funding model. ${ }^{4}$

Following accreditation private GPs and hospital groups will voluntarily sign $\mathrm{NHI}$ service contracts. The frontline of service delivery will remain the district health system. ${ }^{4}$ At primary care level, the focus will be on comprehensive services that include health promotion, disease prevention, treatment, rehabilitative and palliative services. ${ }^{4}$

The medical profession is an important stakeholder when determining the structure and anticipating the impact of a reformed health system. ${ }^{4}$ The participation of private GPs in a health system funded by $\mathrm{NHI}$ is essential to improve access to and quality of primary care. Effective primary care is a prerequisite for a cost-effective healthcare system. ${ }^{1}$

Some sub-Saharan African states have introduced $\mathrm{NHI}$ with varying outcomes. Ghana was the first sub-Saharan Africa country to introduce $\mathrm{NHI}$ in $2003 .^{5}$ The challenge in Ghana has been operational and financial sustainability in the face of cost escalation, inadequate technical capacity, inadequate monitoring mechanisms and broad benefit packages. ${ }^{5}$ 
Nigeria established its $\mathrm{NHI}$ in 2006. Its population coverage is only $10 \%$ as beneficiaries are mostly formal sector employees. ${ }^{6}$ It has proved to be very difficult to implement $\mathrm{NHI}$ in developing economies that have a very large informal sector and poor revenue collection mechanisms. ${ }^{6}$ This has excluded millions of citizens from having access to quality health care. ${ }^{6}$

Previous studies exploring the views of GPs in South Africa have shown mostly negative sentiments towards $\mathrm{NHI}^{7-10}$ The concerns at the time were regarding accreditation, contracting, remuneration, poorly equipped $\mathrm{NHI}$ pilot sites, lack of information on the health packages, impact on private practices in terms of workload, quality of care that would be provided, as well as costs involved to upgrade practices for more space and staff. Loss of clinical autonomy was also a concern in previous research.

Most of these studies, however, were performed prior to the release of the White Paper on NHI. ${ }^{11}$ In December 2015 the $\mathrm{NHI}$ White Paper was published and provided more detail and certainty regarding the future direction of $\mathrm{NHI} .{ }^{11}$ The views of GPs may have evolved in response to the White Paper and no study has explored the views of GPs in the Eastern Cape, which is one of the poorest rural provinces. As NHI becomes more of a possible reality with legislation having been passed, GPs' views might have evolved.

The aim of this study was to explore the perceptions of GPs on $\mathrm{NHI}$ in Chris Hani district, Eastern Cape, South Africa. Specific objectives included:

1. To explore the perceptions of GPs on NHI- how they see, understand and interpret $\mathrm{NHI}$.

2. To explore the factors affecting their willingness to participate.

3. To explore their suggestions to improving the NHI policy.

\section{Methods}

\section{Study design}

This was a descriptive phenomenological qualitative study that used semi-structured interviews.

\section{Setting}

The study was conducted at Chris Hani district in Eastern Cape, South Africa. The district was made up of six municipalities: Engcobo, Emalahleni, Intsika Yethu, Enoch Mgijima, and Inxuba Yethemba. Historically the towns in the district came from the former homelands of Ciskei and Transkei as well as the former Republic of South Africa prior to 1994. The district is mostly rural with high levels of poverty, unemployment and inequality, especially in the former homelands. ${ }^{12}$

There were 74 GPs in private practice in Chris Hani district. ${ }^{13}$ These GPs care for patients who pay via private medical aid or from out-of-pocket cash payments. They provide primary care services and, in some instances, have access to private hospitals for those with insurance. Chris Hani district was not one of the national NHI pilot districts, but some of the GPs might have had prior experience of these pilot sites in other districts.

Some of the private GPs have over a decade of service to their communities. The scope of practice has limitations such as no access to radiology, little palliative or rehabilitative care and their service is generally limited to ambulatory care.

The researcher was also a GP in private practice in Chris Hani district and had a postgraduate Diploma in Family Medicine, which included training in communication and interviewing.

\section{Sample size and selection of respondents}

Purposive sampling of information-rich participants used the following criteria:

- Two GPs from each of the six municipalities to ensure practices serving different parts of the community were selected.

- GPs with a mixed-practice population including both outof-pocket and medical aid patients.

- Any GPs who had previously worked at an NHI pilot scheme.

An initial sample of 12 interviewees was therefore intended, with the option of further interviews if saturation of themes was not obtained. Doctors who were personally known to the researcher were not selected for interview in order to minimise the effect of a prior relationship on the interviews.

\section{Data collection}

Individual interviews were conducted by the researcher. Semistructured interviews were performed using an interview guide. The interview guide explored general views on $\mathrm{NHI}$, views on participating in $\mathrm{NHI}$ and how implementation of $\mathrm{NHI}$ could be improved. The interview guide was reviewed by the supervisor for content and construct before it was used. To explore the perceptions of GPs on $\mathrm{NHI}$, open-ended questions that allowed the interviewees to elaborate and express themselves fully were used. The researcher was trained by the Division of Family Medicine and Primary Care, Stellenbosch University, on how to conduct qualitative interviews. The pilot interview tape was also reviewed by the supervisor and feedback was given.

Participants were invited in advance to participate in the study with a telephone call or email. An information sheet detailing the research topic, aim and objectives was sent to participants by fax or email prior to interviews. Interviews were conducted in neutral venues at a time convenient for the interviewees. Interviews were up to 60 minutes long. The researcher recorded interviews on a digital audio-recorder. All interviews were conducted in English and no translation was needed.

\section{Data analysis}

The interviews were transcribed verbatim by an independent transcriber. Page numbers, line numbers and coding margins were done by the researcher. The transcripts were checked for any mistakes against the original recording before analysis was attempted. Atlas.ti version 8 (https://atlasti.com/) was used to assist with data analysis following the framework method, which had the following steps: ${ }^{14}$

- familiarisation: repeatedly reading the transcripts and re-listening to the audio recordings until familiar with the data;

- thematic indexing: codes were identified inductively from the data and organised into categories;

- indexing: codes were applied to all data transcripts;

- charting: data with the same codes were brought together from all transcripts into one chart; 
- interpretation: each chart was read and the data interpreted so as to establish the nature and range of perceptions.

Any associations between emerging themes were identified. Particular attention was paid to deviant cases that contradicted the main findings, as they might be information-rich sources that brought further understanding.

Reflexivity was accounted for by the researcher taking note of his thoughts, feelings and judgements that could have influenced the collection and interpretation of data during analysis. The analytical process was also supervised, particularly the construction of the thematic index and final interpretation of the data.

\section{Ethical considerations}

Ethical approval for the study was obtained from Health Research Ethics Committee at Stellenbosch University, S17/08/ 124. The research code of the World Medical Association Declaration of Helsinki: Ethical Principles for Medical Research Involving Human Subjects was followed. Written informed consent was obtained from each participant before being interviewed.

\section{Results}

Twelve GPs were interviewed for the study. The participants' age ranged between 31 and 65 years and work experience between 3 and 32 years in private practice. Two participants were female and 10 male. Two participants had master's degrees, four had postgraduate diplomas and six had no postgraduate qualifications. Eleven of the participants were in solo practice and one was in group practice (Table 1).

Results are presented as themes that emerged during the interviews under the following headings:

1. Perceptions of $\mathrm{NHI}$.

2. Reasons to participate in $\mathrm{NHI}$.

3. Ideas on how $\mathrm{NHI}$ could be improved.

\section{GPs' perceptions of $\mathrm{NHI}$}

There was a view that $\mathrm{NHI}$ would benefit people in rural areas and improve health and access to healthcare:

Table 1: Profile of respondents

\begin{tabular}{llllc}
\hline Identifier & Sex & Setting & $\begin{array}{c}\text { Dispensing } \\
\text { licence }\end{array}$ & $\begin{array}{c}\text { Years in } \\
\text { private } \\
\text { practice }\end{array}$ \\
\hline 1. DN & Male & Urban & Yes & 5 \\
\hline 2. BN & Male & Urban & Yes & 16 \\
\hline 3. OS & Male & Rural & Yes & 3 \\
\hline 4. BL & Male & Rural & Yes & 10 \\
5. DM & Male & Rural & Yes & 25 \\
\hline 6. VG & Female & Rural & Yes & 8 \\
7. SJ & Male & Urban & Yes & 21 \\
\hline 8. DS & Male & Rural & Yes & 30 \\
9. CW & Male & Rural & Yes & 6 \\
\hline 10. LN & Male & Urban & Yes & 16 \\
\hline 11. CY & Female & Urban & Yes & 18 \\
\hline 12. MAO & Male & Urban & Yes & 32 \\
\hline
\end{tabular}

'I think, uh, the health of people will definitely be improved, even, uh, pregnant women, the maternity. We do have, at the present moment, people who have to wait for surgery for quite long, you know.' (DM)

'Ja, no, what we understand is that NHI you know, was supposed to come and, uh, improve, uh, health services, especially to the poor so that it includes everybody.' (DM)

$\mathrm{NHI}$ was seen very positively as bringing equity to health care, because with enough resources the healthcare system would be able to provide quality services to the majority of the population:

'And you find out that currently, there's just poor healthcare services to the public sector which serves the majority of the population. So if there's enough resources and there's equitable health care, you see, I do believe most of the population will benefit. I think that's it.' (CY)

There was a view that $\mathrm{NHI}$ would help to reduce patient waiting times in the public sector as some patients could attend private facilities and this would also improve job satisfaction amongst public sector healthcare workers due to a reduced workload:

'You know, and it would decrease what we see in hospitals like overflow and what not. Currently, the problem with clinics is that we don't have doctors there.' (BN)

Patients would benefit from access to a more efficient private sector, where for example there were no medication stock-outs:

'Uh, but quality wise, they will get a better service because they will receive whatever I have ordered as a doctor. Uh, I don't remember asking private and saying I don't have anything and let them go.' (OS)

One participant commented that $\mathrm{NHI}$ would personally benefit him and his family by making financial savings that ordinarily would go to medical aid payments:

'For instance, I have a medical aid which I'm paying 5000and-something rand per month, myself, my wife and my daughter. Now if the NHI suddenly becomes accessible to me as well and I can still see any GP that I want to see, my preferred doctors, and I can still see my preferred neurologist that my daughter goes to every year, then why should I have my medical aid.' (CW)

Respondents saw $\mathrm{NHI}$ as a nationwide revamping of the health system for people in rural areas. NHI was perceived as a way to allow people on disability grants and old-age pensions the same benefits as those on medical aid:

'Well, maybe I'm not adding, I am repeating myself. How I wish, one day, someone would wake up and think that everybody with a disability grant card would have medical aid card as well. That's my wish for this country.' (SJ)

Some participants were of the view that government must make $\mathrm{NHI}$ more of a priority by giving sufficient resources and using those resources efficiently. Respondents felt that $\mathrm{NHI}$ was 
better suited to a country with more employed people, good financial structures and good governance. Participants felt that South Africa does not have that and were not sure where the money was going to come from:

'In the sense that if you look at the number, the amount of money we lose in state-owned enterprises and also the irregular expenditures, the fraudulent things that are taking place in government, if you combine all those things and we minimise our losses and control our fiscals very well, we could achieve that.' (BL)

The other theme that emerged was that of proper local planning. Interviewees were of the view that South African based research and local planning for $\mathrm{NHI}$ was needed rather than importing models from other countries. Some felt that having a sound human resource plan would also be key to making $\mathrm{NHI}$ achievable:

'I think they've gathered the, all the necessary, they've researched about it in other countries which have implemented the programme long ago. I think by now they should know the pros and cons of it.' (LN)

Participants said NHI was not achievable. They felt that the government had failed to provide efficient and effective public health care and would not be capable of a more ambitious task under $\mathrm{NHI}$ :

'I don't understand it really because, from what I've heard so far, I haven't read anything about it, is that basically government will subsidise everyone so that they can have access everywhere. That's the part I don't understand, because they failed doing that in hospitals. Though if they are coming back to it now, how are they going to do that, on what funds?' (VG)

\section{GPs' views on the implications of participating in $\mathrm{NHI}$}

Respondents felt that they were willing to embrace change and give NHI a chance because of the need to make a positive difference in society. They would like to be part of the solution to fixing a broken health system. They felt that NHI was a good cause and would like to help the government to do the right thing:

'Uh I think it's a great idea really. Health, as it is at the moment at this beautiful country, we've got resources but the way it's provided, it's not reaching to the intended recipients, full stop.' (SJ)

GPs were of the opinion that there will be a single payment system under $\mathrm{NHI}$ that would be preferable to dealing with multiple medical aid organisations:

'I do think, uh, there will be things which, uh, probably, uh, be positive, others might be negative. The positive things is that, uh, I think if $\mathrm{NHI}$ comes, it will take also the burden from us. Like us, you know, buying medication and at the same time, we are battling for payment with medical aids. Some of medical aids don't even pay us.' (DM)

One area of uncertainty was the requirement for accreditation of GP practices:
'Ja, I heard about it. It's just that I don't know the nittygrittys of what is that, uh, what kind of infrastructure that they are looking for.' (DM)

Although certain participants were reassured by their previous experience of accreditation for dispensing:

I've heard that, uh, private GPs will be assessed and accredited to participate in $\mathrm{NHI}$, and after my experience earlier in 2003,2004 , when the issue of dispensing licence was introduced, remember, it looked like a big hurdle, but we all went through it and here we are. I think even that accreditation process will go smooth.' (SJ)

GPs wanted to know what the primary care service package would look like and how this would be supported and remunerated:

'Well as I say, till everything is explained, because I don't know who's going to be providing medication, are they going to be having their packages kept in our dispensaries or we have to provide the medication to clients, I don't know how is it going to be.' (LN)

'I think a fixed fee, it is reasonable, neh, to a certain extent, you see. With healthcare, neh, it's a bit dynamic, you see, because there are services that you can say fine, this is the base service that you can offer, you see, but there are those ones where you can say fine, here it will now depend on what sort of, uh, extra inputs that you're going to be putting in the service packages.' (CY)

Doctors were of the view that policy-makers should consult more with healthcare providers to obtain practical and realistic information when planning service packages:

'What I would suggest, uh, before you go to the background, uh, you need to consult those who are at ground level, those who are doing the spade work.' (BN)

Some of the anticipated consequences of a comprehensive primary care service package were that group practices with a multidisciplinary team (e.g. dentists, optometrists or dietitians) might be better able to provide all the services and cope with an increased workload. This might have implications for the financing required to buy more equipment, provide extra space and employ more staff. The relationship between accreditation of practices to provide the package and remuneration to support this was critical and a significant area of uncertainty:

If doctors work as a group, then they are able, you know, to distribute all those other doctors and say you go there, you go there. Unlike as an individual, and even in terms of negotiations, it's better.' (DM)

'Ja, you see, the equipment, uh, we can buy equipment but it also depends what is going to come in because you can't go buy expensive equipment, and at the end of the day, you are unable to pay it back because you'll be financing it probably through banks.' (DM)

'Uhm, in terms of the facility that we have, it means a lot of things need to be turned around. Uh, whether you will have to employ some people because it's going to be a centre for people to come.' (OS) 
'So I need to make sure that for quality purposes, then we must expand, you know, and do all those other things. It's good because it's creating employment for other people, but would that be considered in that package [chuckles]?' (DN)

There were divergent views on the fee structure of service packages with some doctors thinking there must be separate consultation and medication fees, as with most current medical aids. Others thought that the structure of low-cost medical aids that pay a fixed amount for both consultation and medication would be a better model:

'Well, a lot of medical aids are doing it. Discovery says for KeyCare patients for instance, we're going to pay R300 and this must include medicine. So we get our way around it.' (CW)

Delayed payments from the NHI fund were another concern for GPs and would have a negative impact on the quality of services provided. Based on negative experiences with the Government Employees Medical Scheme (GEMS) some doctors were sceptical about the efficiency of payments to GPs under NHI:

'Ja. Uh, then it means from my side from what our experience or what we have seen or what government does and how they-how long did they take to pay you. Somewhere, somehow you must juggle around your finances because you can't buy medicines and get paid three months down the line. I think they must improve that, payment must be done with immediate effect.' (OS)

GPs were concerned about long queues of patients with high expectations compared with what would actually be available under $\mathrm{NHI}$ :

'And now people are going to be expecting everything. Much in the pregnant comes in and say I understand, I want this, I want to know the sex, that is going to take about 30 minutes and the queue is long.' (LN)

Some doctors felt that because healthcare will be free at the point of care, utilisation would increase and doctors might have to extend opening hours:

'As things stand now, I've got opening hours, 8-5. Now somebody calls me at 9, I don't know how that one is going to be addressed with your patients as allocated, or if the case is going to be, how is it going to be, because now you find that the hours have been extended.' (LN)

GPs added that the referral patterns to private hospitals should be made clear as patients would most likely choose to be referred to private hospitals if that option was to be made available under $\mathrm{NHI}$ :

'I don't know how that's going to work because the perception here, most people, if you are going to want, uh, to have a choice between Frontier hospital [public sector district hospital] or private hospital, obviously I will go to private.' (MAO)

The importance of patients valuing what they receive free of charge under $\mathrm{NHI}$ as well as their rights and responsibilities have to be made clear when designing referral pathways:
'An NHI patient comes in, same scenario, and this patient doesn't want to be admitted to Dordrecht Hospital [public sector district hospital]. Can he refuse to be admitted to Dordrecht Hospital, first and foremost?' (CW)

Respondents wanted to admit their private patients to public hospitals:

'If they give us beds. So that if you need to admit, you admit.' (VG)

Doctors said that nurses in clinics must be able to refer patients to NHI accredited private GPs as opposed to the current proposal that private GPs work at government clinics:

'Well, well, I am sceptical about that. I wish the clinics would be managed by primary care healthcare nurses in this country. I wish those primary healthcare nurses be able to refer their problem patients to GPs on the day.' (SJ)

\section{Perceptions on how implementation of NHI could be improved}

GPs did not critique the policy per se but had a number of ideas on how implementation of $\mathrm{NHI}$ could be improved. Doctors wanted to be involved and engaged from the beginning and on an ongoing basis as things evolve:

'But for now, I think we can improve communication on this. It should not be left, uh, with politicians to discuss this and, uh, even just the implementation as well. I think it needs to involve more of everyone, whether you are a GP, whether you are in government.' (DN)

GPs suggested that there should be $\mathrm{NHI}$ teams that go to the district health structures, Independent Practitioner Associations and South African Medical Association branches throughout the country to inform, dialogue and obtain feedback from GPs:

'So I think they can have people with the know-how, full information about what is going on with the $\mathrm{NHI}$, uh, they go to areas where they organise a meeting and have a meeting with doctors.' (BN)

GPs said NHI should be introduced to medical students and academics at medical schools to encourage dialogue and refinement of the concepts of universal coverage and implementation:

'I mean in medical school they must start talking about it. You remember, I'm not sure about your medical school, but where I come from, there used to be those things known as clinical conferences or what-not, whereby you find students are engaging on what is proposed, things that are proposed.' (DN)

GPs would like to be informed about what will be required from them under $\mathrm{NHI}$ :

'So at least, anytime they should actually be telling us that, uh, maybe your practice will look like this if we're going to use you, or we're not going to use you guys, we're going to use, uh, our own infrastructure.' (DM) 
GPs would like to have clear information on how patient allocation will be done as part of capitation under $\mathrm{NHI}$ :

'How the system is going to operate here, I'm not sure. We're not privy to all the information as to how it's going to work.' (CW)

GPs felt that before implementing $\mathrm{NHI}$ the government must improve their healthcare facilities, clinics and hospitals and solve their human-resource challenges:

'Uh, our clinics are not up to scratch. Uh, our hospitals are not up to scratch in terms of infrastructure and the treatment and now the coming issue of human resources.' (OS)

GPs mentioned the problem of staff attitudes in the public sector as a major barrier to quality health care, which needed urgent attention:

'Well, to improve on quality of care, I believe health care, much as it is a science, it's a social science, my belief is on a holistic approach to treatment. So in terms of quality, I believe quality starts with attitude, starts with behaviour. That's where it all starts. It's all about Batho Pele principles.' (SJ)

GPs highlighted the importance of clinical team work and a supportive organisational culture:

'Doctors, I mean we go into the profession to serve, you understand. You come to serve. You find that somewhere along the way, you cannot do your service because the supporting cast, as I said, is not playing their role.' (MAO)

GPs felt that continued medical education for doctors should be freely available to improve the quality of care and standardise competencies between public and private doctors:

Table 2: Summary of key findings

\begin{tabular}{|c|c|}
\hline \multicolumn{2}{|l|}{ Perceptions of NHI policy } \\
\hline $\begin{array}{l}\text { Positive perceptions: } \\
\text { Will improve health equity, } \\
\text { universal coverage and benefit } \\
\text { society } \\
\text { - Will be of particular benefit to } \\
\text { poor and rural communities } \\
\text { Will improve access to higher } \\
\text { quality healthcare }\end{array}$ & $\begin{array}{l}\text { Negative perceptions: } \\
\text { - May suffer from a lack of } \\
\text { governmental administrative } \\
\text { capacity, e.g. in accreditation } \\
\text { and remuneration } \\
\text { - Needs to be informed by a } \\
\text { national human resources } \\
\text { policy }\end{array}$ \\
\hline \multicolumn{2}{|c|}{ Views on implications for GP practice } \\
\hline $\begin{array}{l}\text { Positive implications: } \\
\text { - Funding may enable more } \\
\text { medical equipment and a more } \\
\text { comprehensive primary care } \\
\text { package } \\
\text { - Dealing with one purchaser } \\
\text { and not multiple medical aids }\end{array}$ & $\begin{array}{l}\text { Negative implications/concerns: } \\
\text { - Lack of information about the } \\
\text { primary care package, } \\
\text { accreditation of practices, } \\
\text { registration of patients and } \\
\text { capitation funding scheme } \\
\text { - May disadvantage solo GPs }\end{array}$ \\
\hline \multicolumn{2}{|c|}{ Ideas on how to improve implementation } \\
\hline $\begin{array}{l}\text { - Engage more actively and posit } \\
\text { - Improve quality of government } \\
\text { - Provide free continuing medical } \\
\text { competencies between public a }\end{array}$ & $\begin{array}{l}\text { y with GP organisations } \\
\text { alth facilities and staff attitudes } \\
\text { lucation to standardise } \\
\text { private doctors }\end{array}$ \\
\hline
\end{tabular}

'Because most of us in the private practice, we do attend all these courses but the state must subsidise that, not any individual will go in there and pay for himself. Then it means there must be standard courses that it's a must we attend.' (OS)

The potential for fraud and abuse of the NHI system by both doctors and patients was a concern that needed to be anticipated and addressed:

'The second thing that I'm a bit worried about is that we are giving a lot of power to a lot of desperate people. My view is that I know private doctors that are unethical.' (CW)

Better communication between public and private systems while combining expertise from both sectors with regular interactions was seen as a good way to make $\mathrm{NHI}$ a success:

'I think it's good for the public doctors to know what's happening in the private sector. But what I've seen in places like Queenstown for instance is like zero communication between, even when there's CPD meeting being held, we do not see the public doctors at those CPD events.' (CW)

Doctors added that the public hospitals could improve their quality of care by working with experienced doctors in the private sector:

'Uh look, I mean the main problem now, especially with the public sector now, is quality of care in terms of the expertise, okay. Because if you look now, most of the mature, uh, experienced people are not in the public, you know, I mean they are in the private.' (MAO)

\section{Discussion}

The key findings of the study are summarised in Table 2.

The GPs in this study appeared to be more supportive of the underlying principles and need for the $\mathrm{NHI}$ compared with GPs interviewed from more urban areas. ${ }^{7-10}$ This could be because they serve a poor rural community and were more conscious of the need for a radical reform of the health system, such as the implementation of $\mathrm{NHI}$, that would improve health equity. Even in urban areas it was noted that GPs serving poorer communities were more positive about $\mathrm{NHI}{ }^{10}$

Despite this, GPs in this study shared concerns with other GPs on the financial and administrative capability of government to efficiently deliver $\mathrm{NHI} .{ }^{15}$ They were particularly concerned about the efficiency of payment and remuneration under NHI. A review of sustainability and threats to $\mathrm{NHI}$ in Ghana found operational and financial stability to be challenges. ${ }^{5}$ Nigeria's $\mathrm{NHI}$ had a low budget due to having a high informal sector population. ${ }^{6}$ These challenges might be a problem for South Africa as well given the similarities of the challenges.

Piloting of $\mathrm{NHI}$ in district health services appears to have focused on contracting private GPs to support nurse-led public sector primary care clinics. ${ }^{16}$ This model has become synonymous with what $\mathrm{NHI}$ intends to do and yet the policy document speaks more to the accreditation of private GP practices. This study supports the latter viewpoint, with private GPs in Chris Hani district suggesting that patients be seen in their own accredited private practices rather than using poorly equipped government clinics. They echoed concerns from other GPs about 
the quality of care at government clinics in terms of workload, staff attitudes, infrastructure, equipment and medication supply. ${ }^{9}$ Although GPs suggested that nurse practitioners in public sector clinics could refer patients to accredited private GP practices the intention of $\mathrm{NHI}$ is that all accredited primary care facilities should be able to deliver the same package of care. This implies that all primary care facilities would have access to a doctor and not need to cross-refer. This standard is already included in the ideal clinic policy. ${ }^{17}$

GPs shared the same concerns as GPs elsewhere in terms of needing clarification on the primary care service package and model of remuneration. They had similar ideas on the potential implications such as $\mathrm{NHI}$ favouring group more than solo practice and more multidisciplinary teams. ${ }^{18}$ The need for more interaction, engagement and communication was also echoed in other studies of GPs. ${ }^{7,10}$

\section{Limitations}

Some potential participants excused themselves from the study. This resulted in a gender bias of participants being mostly males. A broader gender mix might have given richer and more varied results for this study. For example, female doctors may be more positive about group practice under $\mathrm{NHI}^{7}$ and it would have been preferable to explore that more in this study. The two female GPs' practices included both rural and urban areas and were broadly similar in terms of experience to the male GPs.

\section{Recommendations}

Policy-makers should have a more proactive approach to introducing $\mathrm{NHI}$ to GPs with engagement and debate on how $\mathrm{NHI}$ implementation could be made a success. Detailed NHI information and plans concerning solo GPs would help to counteract resistance that stems from fear of the unknown. In particular the details of the primary care package, system of remuneration and patient registration need to be clarified.

Further research could focus on how $\mathrm{NHI}$ could use health information systems data from GP practices, clinics and district hospitals for analytics and planning with the end goal of improving quality of primary care in Chris Hani district.

\section{Conclusion}

Rural GPs in the Eastern Cape were quite positive and supportive of $\mathrm{NHI}$ and felt it would have benefits for their practices, patients and communities. They had a number of concerns regarding a lack of detailed information on how $\mathrm{NHI}$ would actually work and the implications of this for solo GPs. They also had concerns regarding the government's capacity to organise NHI and South Africa's tax base to fund NHI. They would like a more proactive and positive engagement with government as plans for $\mathrm{NHI}$ go forward.

Declaration - No financial support was received for this article.

Disclosure statement - No potential conflict of interest was reported by the authors.

\section{ORCID}

Mthetheleli Mbongeni Gaqavu (D) http://orcid.org/0000-00026326-1131

\section{References}

1. Matsoso MP, Fryatt RJ, Andrews G, editors. The South African health reforms, 2009-2014: Moving towards universal coverage. Pretoria: Juta; 2015.

2. Department of Health. National Health Insurance in South Africa Policy Paper [Green Paper]. Pretoria: National Department of Health; 2011. [cited 2019 Feb 11]. Available from https://www.gov. za/documents/green-papers.

3. van Rensburg HCJ. A history of health and health care in South Africa: 1652-1994. In: van Rensburg HCJ, editor. Health and health care in South Africa. Van Schaik: Pretoria; 2012. p. 61-120.

4. Department of Health. National health insurance for South Africa: towards universal health coverage. Pretoria: Department of Health, Republic of South Africa; 2018.

5. Alhassan RK, Nketiah-Amponsah E, Arhinful S. A review of the national health insurance scheme in Ghana: what are the substantial threats and prospects? PLOSONE. 2016;11(11):e0165151, doi.10.137/ journal.pone.0165151.

6. Adewole DA, Osungbade KO. Nigeria national health insurance scheme: A highly subsidised health care program for a privileged few. Int J Trop Dis Health. 2016;19(3):1-11. Doi:10.97334/IJTDH/ 2016/27680.

7. Moosa S, Luiz J, Carmichael T, et al. Insights of private general practitioners in group practice on the introduction of National health Insurance in South Africa. Afr J Prm Health Care Med. 2016;8(1):a 1025, doi:10.4102/phcfm.v8i1.1025.

8. Surender R, Van Niekerk R, Hannah B, et al. The drive for universal healthcare in South Africa: views from private general practitioners. Health Policy Plan. 2015;30:759-757. doi:10.1093/heapol/ czu053.

9. Surrender R, Van Niekerk R, Hannah B, et al. Is South Africa advancing towards national health Insurance? The perspectives of general practitioners in one pilot site. S Afr Med J. 2016;106(11):1092-1095.

10. Mathew S, Mash R. Exploring the beliefs and attitudes of private general practitioners towards national health insurance in Cape Town, South Africa. BMC Health Services. 2018 In Press.

11. Department of Health. National health insurance [White Paper]. Pretoria: Department of Health, Republic of South Africa; 2015.

12. Eastern Cape Socio Economic Consultative Council. [cited 2019 Feb 11th]. Available from https://www.ecsecc.org .

13. Medpages doctors list in Engcobo. Sakhisizwe, Intsika Yethu, Emalahleni, Enoch Mgijima and Inxuba Yethemba [cited 2017 Apr 9th]. Available from www.medpages.co.za.

14. Mabuza LH, Govender I, Ogunbanjo GA, et al. African primary care research: qualitative data analysis and writing results. Afr $J$ Prm Health Care Fam Med. 2014;6(1):a640, doi:10.4102/phcfm.v6i1. 640.

15. Van den Berg E. National health insurance implications for medical practice. S Afr Fam Pract. 2011;53(6):601-604.

16. Matsoso MP, Fryatt R. National health insurance: The first 18 months. S Afr Med J. 2013;103(3):156-158. doi:10.7196/SAMJ.6601.

17. Hunter JR, Asmall S, Ntshengedzeni MR, et al. The ideal clinic in South Africa: progress and challenges in implementation in South African health review. Cape Town: Health Systems Trust; 2017.

18. Moosa S, Luiz J, Carmichael T. Introducing a national health insurance system in South Africa: A general practitioner's bottom-up approach to costing. S Afr Med J. 2012;102(10):794-797. doi:10.7196/SAMJ. 6072. 